\title{
Denmark Wind Energy Programme
}

\section{Shen, Wen Zhong}

\section{Published in:}

Renewable Energy in the Service of Mankind

Link to article, DOI:

10.1007/978-3-319-17777-9_84

Publication date:

2015

Link back to DTU Orbit

Citation (APA):

Shen, W. Z. (2015). Denmark Wind Energy Programme. In Renewable Energy in the Service of Mankind (Vol. 1, pp. 941-949). Springer. https://doi.org/10.1007/978-3-319-17777-9_84

\section{General rights}

Copyright and moral rights for the publications made accessible in the public portal are retained by the authors and/or other copyright owners and it is a condition of accessing publications that users recognise and abide by the legal requirements associated with these rights.

- Users may download and print one copy of any publication from the public portal for the purpose of private study or research.

- You may not further distribute the material or use it for any profit-making activity or commercial gain

- You may freely distribute the URL identifying the publication in the public portal

If you believe that this document breaches copyright please contact us providing details, and we will remove access to the work immediately and investigate your claim 


\title{
Denmark Wind Energy Programme
}

\author{
Wen Zhong Shen \\ Department of Wind Energy, Nils Koppels Alle, Building 403, Technical University of Denmark, \\ 2800 Lyngby, Denmark; E-mail: wzsh@dtu.dk
}

Key Words: Wind turbine aerodynamics, Wind turbine aero-acoustics, Wind turbine design

\begin{abstract}
In this paper, a summary of some ongoing wind energy projects in Denmark is given. The research topics comprise computational model development, wind turbine design, low noise airfoil and blade design, control device development, wake modelling, and wind farm layout optimization.
\end{abstract}

\section{Introduction}

Wind energy is developing very fast in the world. To reduce $\mathrm{CO}_{2}$ emission from fossil energy and alleviate global warming, governmental targets in developing wind energy are very ambitious in most countries. For example, in Denmark, electricity production is forecasted to reach 50\% from wind energy in 2020 and $100 \%$ from renewable energy in 2050 . This means there will be important installations of both onshore and offshore wind turbines in the near future. The implementation of wind turbines is accompanied with challenge and research related to both onshore and offshore wind energy developments. For onshore wind energy development, the main challenge is the noise issue. While for offshore wind energy, it is mostly to reduce the cost of energy as the cost of offshore wind energy is very much as compared to onshore wind energy.

In Denmark, most of wind energy projects are funded by the following funding programmes: FP7 of EU, Energy technology Development and Demonstration Programme (EUDP) of the Danish Energy Agency, Danish High Technology Fund, and Strategic Research programme (DSF) of the Danish Ministry of Research, Innovation and High Education. Each year a number of between 10 and 20 wind energy projects receive funding. The funded projects can be pure research, or pure product development and demonstration. It can also be both research and demonstration. The duration of the projects is between 2 and 6 years.

The ongoing wind energy projects in Denmark comprise the following topics: computational model development, offshore wind turbine design, low noise wind turbine rotor design, control device development (such as trailing edge flaps, vortex generators, etc.), wake model development and wind farm layout optimization.

In the paper, a summary of the above mentioned ongoing research topics, especially in the projects coordinated by DTU Wind Energy, will be given. To illustrate, a number of selected results will be presented.

\section{Computational models}

In wind energy research, there are different types of computational methods that are currently being used for predicting the performance of wind turbines, from simple methods based on Blade Element Momentum (BEM) theory [1] to fully 3D Computational Fluid Dynamics (CFD) methods [2]. BEM is very simple and easy to run on a personal computer, but it has limitations and relies on the employed airfoil data which should be corrected for 3D rotational effects [3] and tip effects [4]. Fully 3D CFD are quite expensive and at the moment it is often used for steady computations. Thus intermediate methods are being developed. Among others, the $Q^{3} U I C$ [5] and MIRAS [6] codes are the two new codes developed at DTU. The former is a quasi-3D steady/unsteady viscous-inviscid interaction code using strong coupling and is used to calculate the performance of airfoils. To illustrate its performance, computations are carried out for the NACA632xx airfoils at a Reynolds number of $3 \times 10^{6}$. From the comparisons presented in Figure 1 , it is seen that $Q^{3}$ UIC predicts very well the performance for both lift and drag coefficients. 


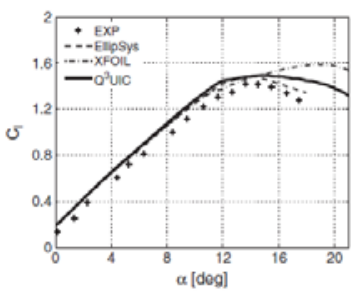

(a)

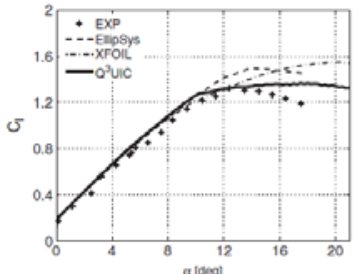

(c)

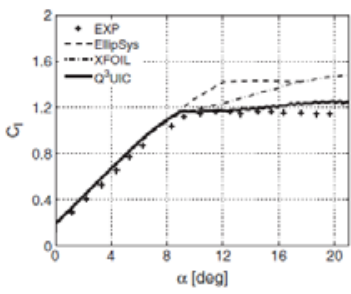

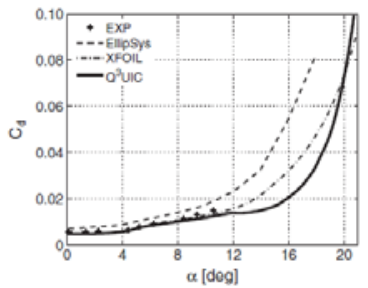

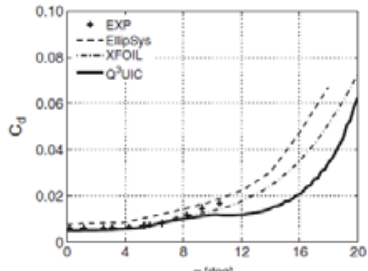

(d)

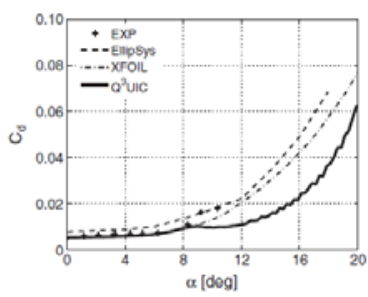

Figure 1: Lift and drag coefficients of the NACA632xx airfoils at a Reynolds number of $3 \times 10^{6}$. (a, b) 15\%; (c, d) 18\%; (e, f) 21\%.

The latter method is based on a three-dimensional panel method using a surface distribution of quadrilateral singularities with a Neumann no penetration condition. Viscous effects inside the boundary layer are taken into account through the coupling with the quasi3D integral boundary layer solver $\mathrm{Q}^{3} \mathrm{UIC}$. A free-wake/mixed-wake model is employed to simulate the vorticity released by the blades in the wake. To illustrate its performance, computations are carried out for a $2.3 \mathrm{MW}$ NM80 wind turbine. In Figure 2, the power and thrust coefficients are well predicted as compared to measurements.

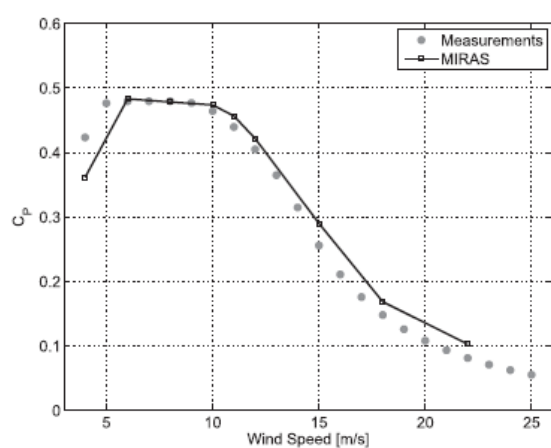

(a)

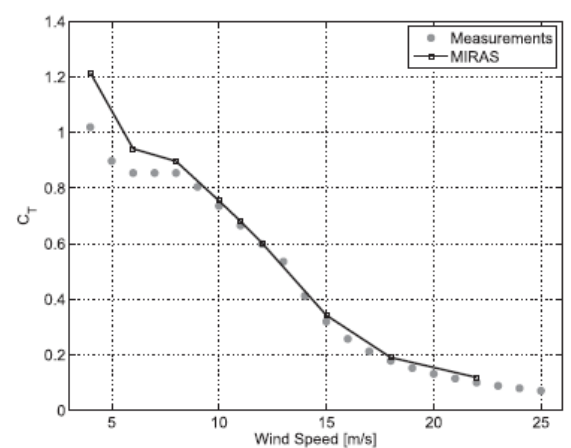

(b)

Figure 2: Power and thrust coefficient of the 2.3 MW NM80 turbine.

\section{Wind turbine design}

Design of efficient and low cost wind turbines is the focus of the current wind energy researches in many countries as offshore wind energy is still very expensive. One way to reduce the cost is to increase the size of wind turbines. The commercial single turbines are reaching $8 \mathrm{MW}$ [7] and the size of research turbines reaches $20 \mathrm{MW}$ [8]. With this increase many aerodynamic and structure problems may appear. To illustrate the activities, the surface pressure of a $20 \mathrm{MW}$ turbine with $130 \mathrm{~m}$ blade which is designed using an integrated airfoil and blade design method developed in [8] is plotted in Figure 3. 


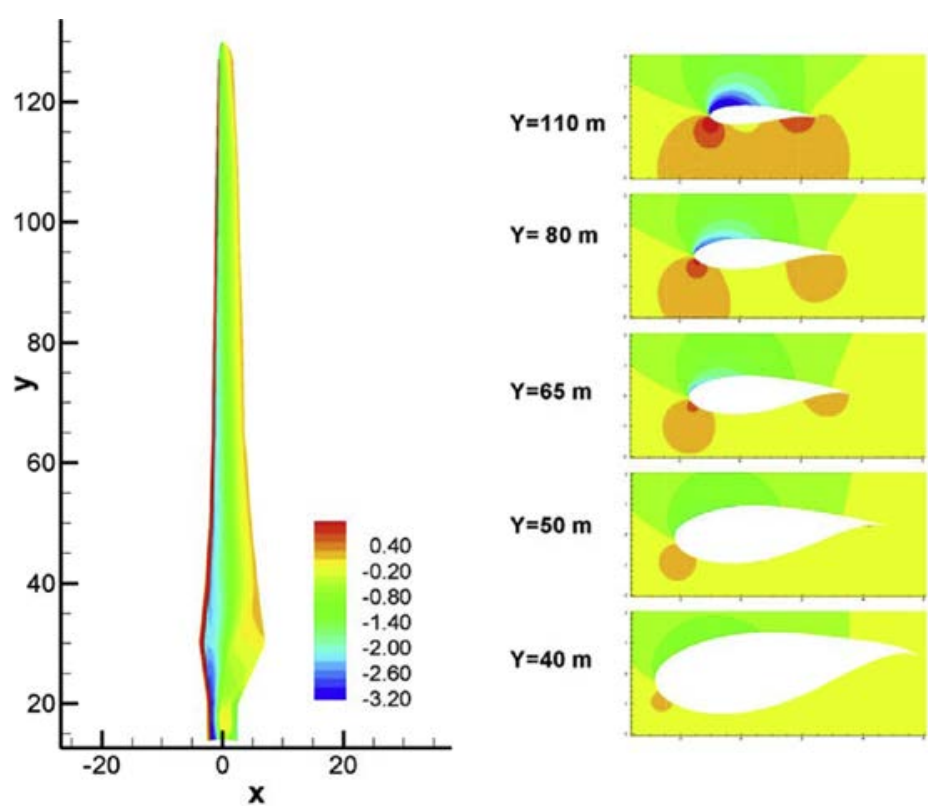

Figure 3: Surface pressure and pressure contour at 5 different cross-sections

For onshore wind energy, most of wind energy developments are focusing on low noise wind turbine airfoil and blade design. In Figure 4 the aerodynamic and aero-acoustic performance of the low noise CQU-DTU-LN118 airfoil [9] is shown. From the figure, it is seen that the CQU-DTU-LN118 airfoil has high aerodynamic performance and low noise emission than the NACA64618 airfoil which is used to construct modern wind turbine blades.
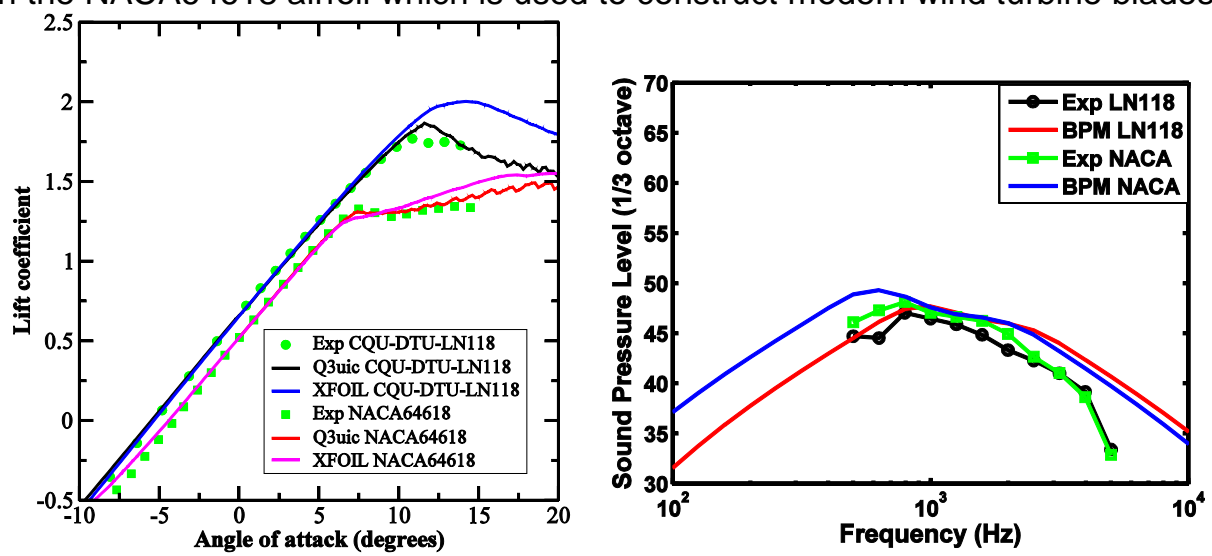

Figure 4: Lift coefficient (left) and sound pressure level in $1 / 3$ octave at a wind speed of 45 $\mathrm{m} / \mathrm{s}$ and $\mathrm{Cl}=0.50$ (right) for the CQU-DTU-LN118 and NACA64618 airfoil.

\section{Control devices}

Control devices are often used to optimize power output and alleviate loads on turbines. In the recent researches, vortex generators [10] and trailing edge flaps [11-12] are the two main focuses. Due to the page limitation, no more discussion is presented. For more details, the reader is referred to [10-12].

\section{Wake modelling}

Wind turbines are often clustered together into so-called wind farms. The performance of the wind turbines in wind farms is important to be predicted for power predictions and/or wind farm control. The most used methods are the Actuator Disc and Actuator Line models implemented in a Navier-Stokes solver for Large-Eddy Simulation. To illustrate, the actuator line model is applied to simulate the performance of the MEXICO rotor with a radius of $2.25 \mathrm{~m}$ [13]. In Figure 5, the axial, radial and tangential velocity at a radial position of $1.848 \mathrm{~m}$ and 9 o'clock is plotted against PIV measurements [14]. Good agreement is seen. In Figure 6, the flow past three $2 \mathrm{MW}$ Tjæreborg turbines in tandem is simulated using the Actuator Line 
technique. From the figure, wake interactions are seen clearly but different when the separation distance between the three turbines is $4 D$ and $6 D$.
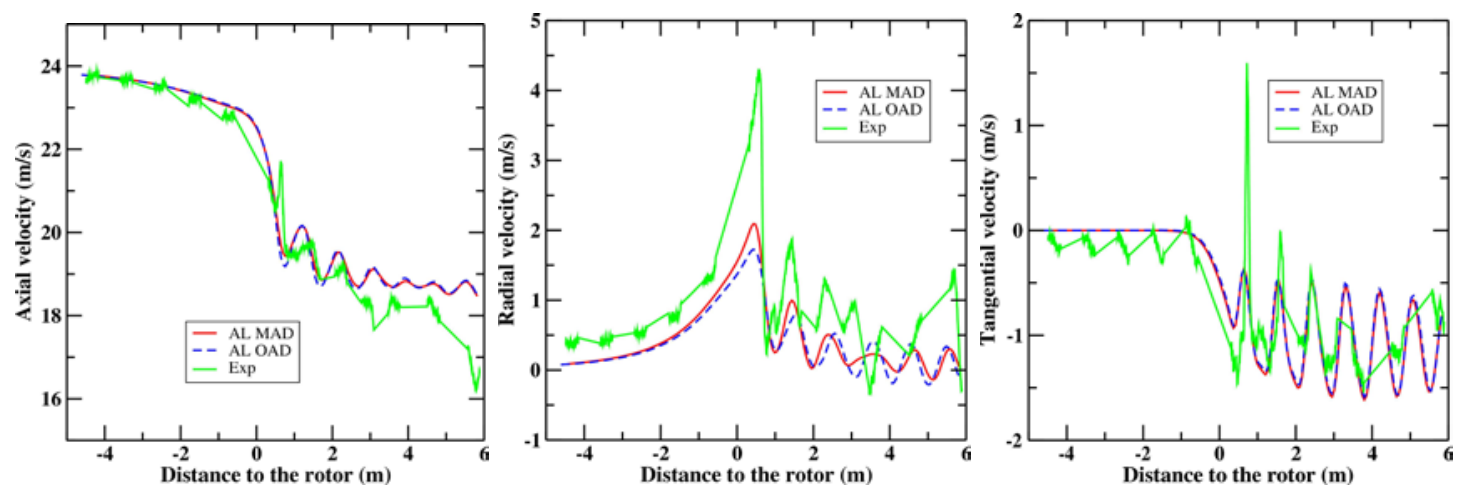

Figure 5: Axial, radial and tangential velocity along the line in the axial direction at $r=1.848 \mathrm{~m}$ and 9 o'clock for the MEXICO rotor at a wind speed of $24 \mathrm{~m} / \mathrm{s}$.

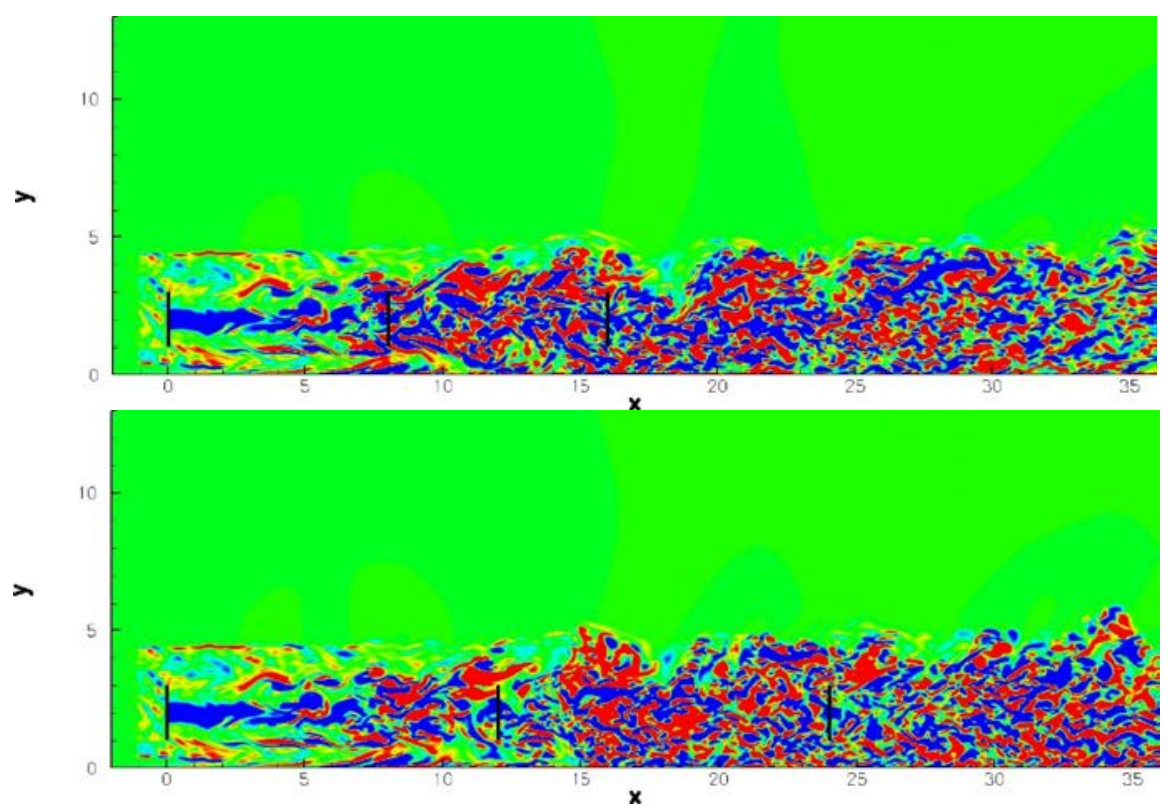

Figure 6: Vorticity plot of three 2MW Tjæreborg turbines in tandem at a hub wind speed of 10 $\mathrm{m} / \mathrm{s}$ at separation distances of $4 \mathrm{D}$ (up) and 6D (down).

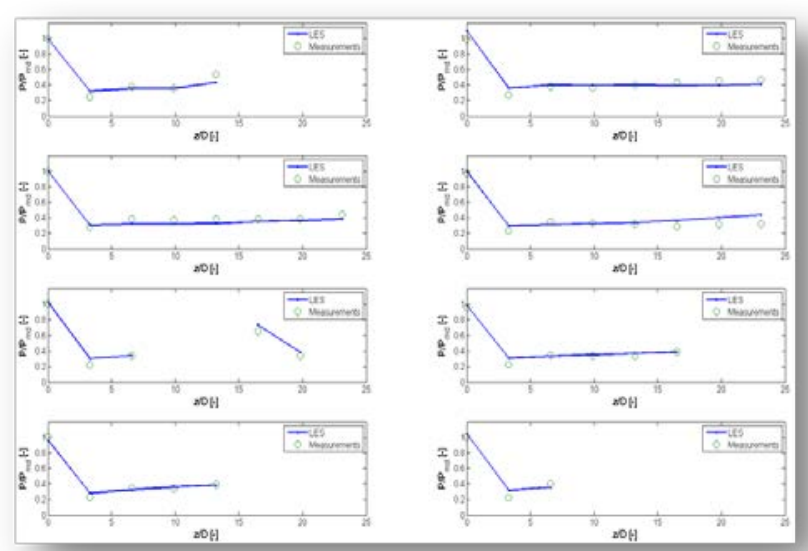

Figure 7: Power performance of the 48 wind turbines in the lillegrund wind farm.

For wind farm predictions [15], the Actuator Disc model is applied to simulate the performance of the Lillegrund wind farm with 48 Siemens $2.3 \mathrm{MW}$ turbines. Good agreement with the measurements is seen. 


\section{Wind farm layout optimization}

Wind farm layout optimization is an essential step for planning wind farms. The technical development has essentially two branches of optimization algorithm and wake model. At DTU, a new random search (RS) algorithm based on continuous formulation has been developed recently [16], which starts from an initial feasible layout and then improves the layout iteratively in the feasible solution space. It can serve both as a refinement tool to improve an initial design by expert guesses or other optimization methods, and as an optimization tool to find the optimal layout of wind farm with a given number of wind turbines (WTs). To illustrate the performance of the algorithm, optimization is made for the Danish Horns Rev 1 wind farm with 80 Vestas $2 \mathrm{MW}$ turbines. From the figure, it is seen that slight improvements have been obtained.
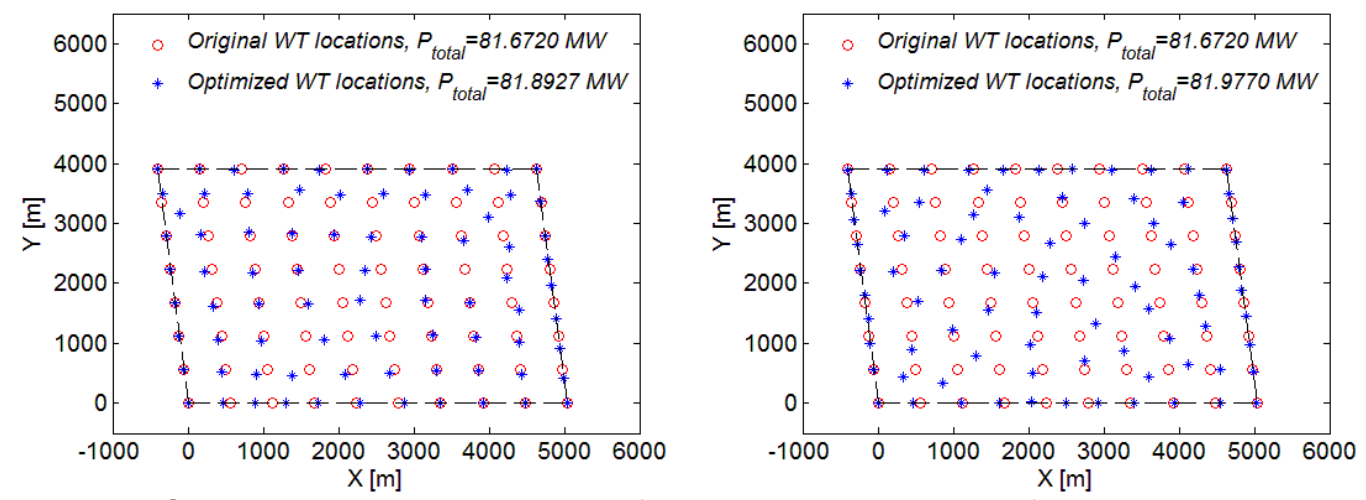

Figure 8: Original and optimized layouts for the Horns Rev 1 wind farm with 80 Vestas 2 MW turbines started from the original layout (left) and from a random layout (right)

For installing wind turbines in complex terrain, CFD methods should be used because the wind resources in complex terrain are often difficult to be determined. Different levels of complexity can be used. Steady RANS/time-averaged LES simulations for the complex terrain should be first performed. Based on the obtained results, layout optimization with improved wake models is then performed. To illustrate the development, wind farm layout optimization is made for a Gaussian hill of $200 \mathrm{~m}$ height and $200 \mathrm{~m}$ hill half-length at the mid-height of the hill. In figure 9 , results of the optimization with $252 \mathrm{MW}$ V80 Vestas wind turbines at a Weibull distribution with $A=10$ and $k=2.3$ (a mean wind speed of $8.9 \mathrm{~m} / \mathrm{s}$ ) for wind for one or two wind directions.
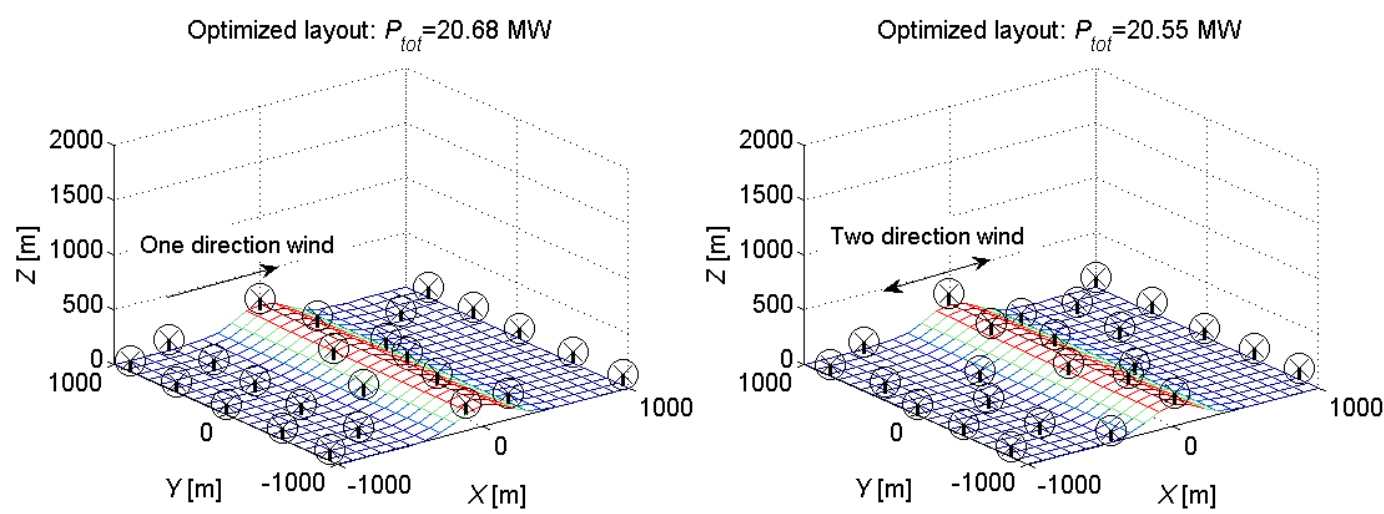

Figure 9: Optimized layouts of the WF with 25 WTs with maximal 100000 evaluations.

\section{Concluding remarks}

This paper gives an overview on some ongoing research activities in Denmark. In general, the research environment in wind energy and renewable energy in Denmark is very good. We hope such investment will continue in the way to increase the penetration of wind energy and renewable energy in the global energy consumptions. 


\section{Acknowledgements}

We gratefully acknowledge the support from the Danish Council for Strategic Research under the projects (09-067216, 10-094544 and 12-130590), the Energy Technology Development and Demonstration Program under projects (63011-0190, 64011-0094, 64012-0146, 640130405), the Danish National Advanced Technology Foundation (028-2007-3) and EU-FP7 projects (EU-2012-308974).

\section{References}

[1] H Glauert. Airplane propellers. In Aerodynamic theory Durant WF (ed) Dover New York 169-360, 1963.

[2] NN Sørensen, JA Michelsen, S Schreck. Navier-Stokes predictions of the NREL phase VI rotor in the NASA Ames $80 \mathrm{ft} \times 120 \mathrm{ft}$ wind tunnel. Wind Energy 2002, 5: 151-169.

[3] $\mathrm{H}$ Snel, $\mathrm{T}$ van Holten. Review of recent aerodynamic research on wind turbines with relevance to rotorcraft. AGARD Report CP-552, chap. 7: 1-11, 1995.

[4] WZ Shen, R Mikkelsen, JN Sørensen, Ch Bak. Tip loss corrections for wind turbine computations. Wind Energy 2005, 8: 457-475.

[5] NR Garcia, JN Sørensen, WZ Shen. A strong viscous-inviscid interaction model for rotating airfoils. Wind Energy 2013, 28 pages, DOI: 10.1002/we.1677.

[6] NR Garcia, JN Sørensen, WZ Shen. Validation of a three-dimensional viscous-inviscid interactive solver for wind turbine rotors. Renewable Energy 2014, 70: 78-92.

[7] http://www.sunwindenergy.com/news/dong-and-vestas-test-8-mw-turbine-together

[8] WJ Zhu, WZ Shen, JN Sørensen. Integrated airfoil and blade design method for large wind turbines. Renewable Energy 2014, 70: 172-183.

[9] JT Cheng, WJ Zhu, A Fischer, NR Garcia, J Madsen, J Chen, WZ Shen, "Design and validation of the high performance and low noise CQU-DTU-LN1 airfoils", Wind Energy 2013, DOI: 10.1002/we.1668.

[10] CM Velte, MOL Hansen. Investigation of flow behind vortex generators by stereo particle image velocimetry on a thick airfoil near stall. Wind Energy 2013, 16: 775-785.

[11] WJ Zhu, T Behrens, WZ Shen, JN Sørensen. Hybrid Immersed Boundary Method for Airfoils with a Trailing-Edge Flap. AIAA Journal 2013, 51: 30-41.

[12] A Fischer, HA Madsen. Load alleviation potential with trailing edge flaps for turbines in wake operation. Proceedings of the ICOWES 2013 conference, pp. 102-112.

[13] J Schepers, H Snel. Model experiments in controlled conditions. ECN-E-07-042, ECN, 2007.

[14] WZ Shen, WJ Zhu and JN Sørensen. Actuator line / Navier-Stokes computations of flows past the MEXICO rotor: Comparisons with Detailed Measurement. Wind Energy, Vol. 15(5), pp. 811-825, 2012.

[15] K Nilsson, S Ivanell, KS Hansen, R Mikkelsen, JN Sørensen, S Breton, D Henningson. Large-eddy simulation of the Lillegrund wind farm. Wind Energy 2014, DOI: 10.1002/we.1707. 